\title{
On the electrical aftercurrents of transversely magnetized iron rods
}

\section{Prof. H. Streintz}

To cite this article: Prof. H. Streintz (1878) On the electrical aftercurrents of transversely magnetized iron rods, Philosophical Magazine Series 5, 5:29, 160-160, DOI: $10.1080 / 14786447808639405$

To link to this article: http://dx.doi.org/10.1080/14786447808639405

曲 Published online: 13 May 2009.

Submit your article to this journal $[\pi$

Џ Article views: 2

Q View related articles $₫$ 


\section{ON THE ELECTRICAL AFTERCURRENTS OF TRANSVERSELY}

MAGNETIZED IRON RODS. BY PROF. H. STREINTZ.

The experiments referred to in this paper were carried out by the author in conjunction with Dr. F. Streintz.

The phenomenon was discovered by Villari, that in a rod of iron or steel through which a galvanic current has passed, when agitated after the interruption of this current, a galvanic current is again generated the same in direction as that originally conducted throngh the rod. He subsequently investigated some properties of these aftercurrents, and gave an explanation of the phenomenon:-namely, that the rod is transversely magnetized by the current; and if we employ the notion of molecular magnets, these arrange themselves in concentric circles around the axis of the rod. Now, if the rod be agitated after the interruption of the current, the molecular magnets obey the direction-force which tends to mingle them again irregularly. We can here avail ourselves of the representation of the molecular magnets returning to the positions which they had before the action of the current. Now, in this return they generate in the rod an induction-current, to which Villari gives the name of "agitation-current," but which may with equal suitableness be designated as an aftercurrent.

Afterwards $\mathrm{H}$. Herwig studied the properties of transverse magnetism on iron tubes.

The author now shows that in a very simple manner the quantity of the magnetizing force can be calculated which is exerted upon the molecular magnets by the current originally conducted through the rod. Starting from Biot and Savart's theorem, that a rectilineal current of infinite length acts upon a pole of a magnet with a force inversely proportional to the perpendicular distance of the pole from the conductor, the problem is reduced to one of the plane ; so that we have to calculate the action of a cireular surface with uniform mass (the rods investigated had a circular cross section) upon a mass-point situated in the surface.

In accordance with the laws of force previously stated, however, a circular line with uniform mass exerts no action on a point situated in the enclosed surface, while it acts on an external point in the same plane as if the mass of the circle were collected in the centre.

Now by this the calculation becomes very simple, and we obtain, as the force which is exerted upon a magnetic pole situated at the distance $r$ from the axis, $p=\frac{k r}{a^{2}}$, in which $k$ is a constant, and $a$ the semidiameter of the rod. The total moment upon all the molecular magnets contained in the rod is then $R=K l a$, where $K$, again, is a constant, and $l$ denotes the length of the rod.

The author has also investigated by experiment the properties of the aftercurrents; and in so doing he found some confirmed which could be foreseen from the theoretical developments, and also discovered various other properties, some of them indeed very striking, which could not have been determined à priori.-Kaiserliche Akademie der Wissenschaften in Wien, math.-naturw. Classe, Dec. 13, 1877. 